\title{
MODELING LEADERSHIP EFFECTS AND RECRUIT TYPE IN AN ARMY RECRUITING STATION
}

\author{
Edward L. McLarney \\ ATZL-NSC-WARSIM \\ 410 Kearney Ave \\ Ft. Leavenworth, KS 66027, U.S.A. \\ J.O. Miller \\ Kenneth W. Bauer, Jr. \\ Dept. of Operational Sciences \\ Air Force Institute of Technology \\ Wright-Pat. AFB, OH 45433, U.S.A.
}

\author{
Robert Fancher \\ Headquarters, USAREC \\ ATTN: RCPAE-RP \\ 1307 Third Avenue \\ Ft. Knox, KY 40121-2726, U.S.A.
}

\begin{abstract}
Army recruiters have an uphill battle recruiting wellqualified volunteers into military service. With a prospering economy, there are many alternatives to joining the military, and all services are having difficulty recruiting young people. United States Army Recruiting Command (USAREC) sponsored our research in simulating the workings of an Army recruiting station in an effort to help understand more about the recruiting process. Specifically, USAREC wanted a management tool to examine the effects of changing a variety of controllable factors on the way an individual recruiting station performs. We focused this study on the effect of recruiting station commander leadership on recruiting productivity, and the differences in processing times and success rates for different types of applicants (potential recruits). This study added capability to a previous simulation model developed at the Air Force Institute of Technology (AFIT) (Cordeiro and Friend 1998). Cordeiro \& Friend's model depicted an Army recruiting station with three types of recruiters, and a single (average) recruiter type. For the current work, we needed to gather pertinent data on the effects of leadership and on the differences between different applicant types. In addition, we needed to incorporate the new data into the simulation model. The remainder of this paper includes an overview of the recruiting process, considerations for modeling leadership effects and applicant types, a discussion of incorporating these features in the simulation, a brief look at some simulation output, and some future research interests.
\end{abstract}

\section{RECRUITING PROCESS}

Army recruiters produce leads for new applicants two ways. First, they prospect for new applicants by visiting high schools or calling potential candidates on the telephone. Second, an applicant can walk into the recruiting station from off the street. From this point, the applicant enters a sales process (to convince them the Army is right for them), proceeds to processing (testing, paperwork, etc.), enters the Delayed Entry Program (DEP), and finally joins the Army. The applicant may drop out or fail to be qualified at any point during the process. A flow chart of the recruiting process is given in Figure 1.

The flowchart in Figure 1 shows the recruiting process as simulated. The three dark boxes at the top of the chart show the things the recruiters do - either prospecting for new applicants, guiding an applicant through the process, or conducting ancillary duties. The remainder of the diagram shows the steps an applicant must go through, from entering the system, through sales, processing, and DEP sustainment, to joining the Army. Note that some steps (moral waiver, medical waiver) do not occur for those who do not need them. For example, if a candidate has a clear bill of health, they will not need a medical waiver. Also note that the applicant may drop out at any point during the process. The simulation model mirrors the above flowchart's process flow.

Cordeiro and Friend (1998) used the SIMPROCESS modeling language by the CACI Company to implement a model of an individual Army recruiting station. SIMPROCESS is a multiple-level icon-based process modeling package. To define basic process flow, the analyst drags and drops icons representing various events and activities from a palette onto the simulation screen. Parameters for these events and activities are easily entered by clicking on the icons. Macro-level processes may be defined, which may contain subordinate processes, with several levels of detail. Further flexibility is provided through the ability to incorporate user-written code (using a subset of CACI's MODSIM language) at nearly any point in the model. 


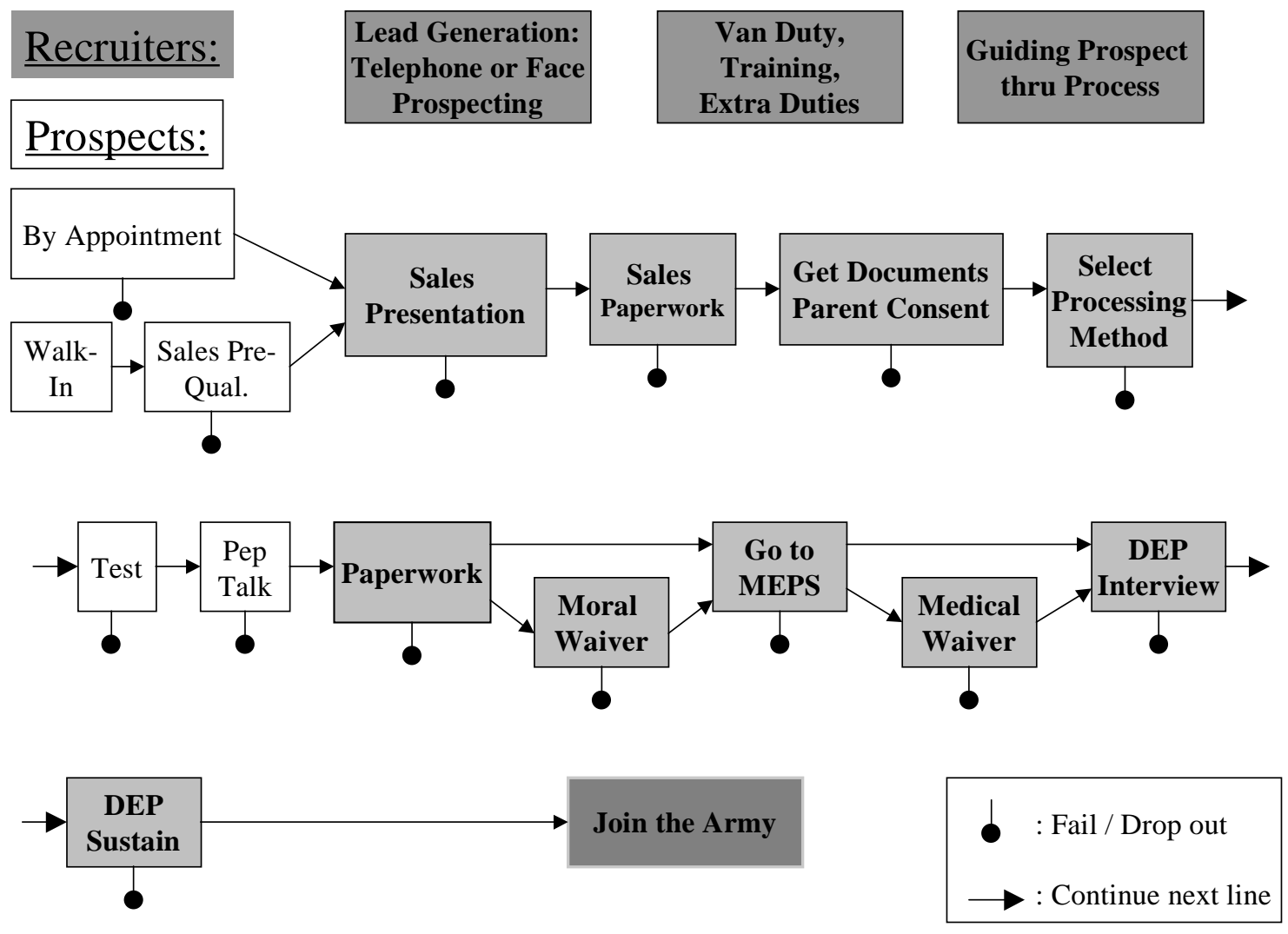

Figure 1: Recruiting Process

Cordeiro and Friend's (1998) model focused on the individual recruiters with the purpose of defining the relationship between various recruiter tasks and the end product-qualified Army recruits. The task at hand for this study was measuring and incorporating leadership effects on productivity into the model, as well as expanding the model to account for differences in applicant types.

\section{LEADERSHIP EFFECTS}

We began investigating leadership effects by researching past work in leadership analysis and modeling. Specifically, we wanted to find successful methods of measuring the effects of leadership. We found a multitude of anecdotes by military retirees, who gave advice on what had worked for them over the years. While this was excellent background material, it did not provide a measurement structure. In addition, we sought out popular leadership theories, such as Total Quality Management (TQM). However, they only gave advice and provided no scientific leadership measurement methods. Finally, we researched how previous military models implemented leadership. For the most part, previous models had a single qualitative factor for leadership, which the analyst scored arbitrarily on scales such as "poor, fair, good, excellent."
We view leadership as more complicated than reflected in such an approach, and for our analysis, we sought a much more detailed depiction of leadership, with many different aspects. With the previously-named sources providing little more than background material, we turned to behavioral analysts at AFIT who suggested several measurement techniques. We theorized that two factors had strong possibilities of influencing recruiting outcomes: leader/recruiter interactions, and recruiter personality traits.

To measure leader/recruiter interactions, we decided to use a framework called "Goal Setting Theory," (Locke and Latham 1990). The basic idea in goal setting theory is that if leaders set clear, achievable, understandable goals, their subordinates will perform in an efficient manner. This hypothesis was supported by many of the anecdotes and advice described earlier. We used Locke and Latham's goal setting questionnaire as a starting point for the current survey; however, we adapted some questions to be more applicable to the military mindset. The great benefit of adapting the goal setting survey was that it was based on an established and credible theory in the behavioral analyst community. We incorporated the adapted questions into our survey, categorized the questions into several groups, and calculated group scores by summing individual scores. The question groups are shown in Table 1 . 
Table 1: Goal Setting Markers

\section{Primary Categories}

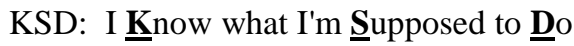

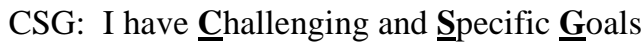

RFG: I have the $\underline{\text { Resources }} \underline{\text { For my }} \underline{\text { Goals }}$

FBK: I get $\underline{\mathbf{F} e e d \underline{\mathbf{B}} \text { ack }}$ about my goals

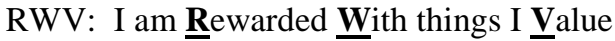

\section{Secondary categories}

SUP: My boss is $\underline{\text { SUPportive }}$

ACC: I $\underline{\mathbf{A C C}}$ ept that my goals are important.

The above categories of questions were used to measure the effect of leaders on subordinates. The primary categories came from goal setting theory, while the secondary categories were adopted from other leadership theories. Although the secondary categories were not measured by the goal setting questionnaire, they appeared to apply to the problem at hand.

In addition to leadership effects, we theorized individual recruiter traits influenced productivity. We were assisted in this area by behavioral analyst theories as well. We used three of the "Big Five" personality markers as described by Lewis R. Goldberg (1998). Big Five developers hypothesize that most personalities can be described by five measures: Extraversion, Agreeableness, Conscientiousness, Emotional Stability, and Intellect/Imagination. For this study, we chose to use Extraversion, Agreeableness, and Conscientiousness as our measures. We theorized that the first three measures would tell us the most about differences between recruiters, and that the remaining two would be less significant. Goldberg provided suggested questions for measuring each trait, which we modified slightly to fit the military mindset. In addition, we designed a supporting measure called self efficacy, to measure the confidence a recruiter had that he or she could succeed at the mission.

We completed the survey by defining two outcome measures: the amount of initial recruiting interviews conducted per week, and the number of contracted recruits achieved in the last six months. Recruiters report these numbers on a regular basis, so we knew they would be able to respond accurately and with a minimum of effort. In addition, we included several demographic markers, such as recruiting station location, time as a recruiter, recruiter gender, etc. A behavioral analyst from AFIT, MAJ Paul
Thurston, provided advice on behavioral theories, and recruiting experts from USAREC provided advice on content and recruiting technical language. We administered the approved survey to 26 recruiters from the local recruiting company and report these results in this paper. Subsequently, we mailed the survey to over 500 recruiters across the country. The complete survey can be found in McLarney (1999).

The sponsor, USAREC, also wanted the model to be able to handle eight different applicant types based on gender (male/female), high school graduation status (grad/senior), and Armed Services Vocational Aptitude Battery (ASVAB) score (high/low). We needed to know how process durations and probabilities of failing/dropping out varied by applicant type. This data was largely unavailable, however USAREC was able to provide "conversion data," which gave the probabilities of making it between several selected checkpoints in the recruiting process. Conversion data was broken down by ASVAB score and high school status, but not by gender. The remaining data (process durations by applicant type) was simply unavailable. Recruiters currently record the dates that steps in the process occur, however, they do not record how many minutes or hours a particular step takes them. Recruiters are currently being issued laptop computers, which will be used to help track (among many other things) process durations. This data gathering process will be lengthy, since it can take up to a year to get an applicant contracted. Since a data gathering process was being fielded, we opted to simply give the model the capability of incorporating different durations and probabilities for eight applicant types. We left the measurement of these parameters up to USAREC in the years ahead.

A final and exciting concept is to relate process durations with the leadership and personality factors already described. The idea involves relating process times with leadership and personality results by directly modifying model parameters to account for various leadership/personality factors for an individual recruiting station. We developed a methodology for correlating process durations with leadership and personality measures, as outlined in the following section.

\section{IMPLEMENTING MODEL CHANGES}

To implement the eight different applicant types in the model, we needed data to define model parameters for each applicant type for processing times and probabilities of dropping out at each step of the recruiting process. Due in part to a SIMPROCESS limitation not allowing the use of arrays, we read-in eight sets of parameter data at the beginning of a set of replications, and assigned each entity its own copy of the applicable data set. Each entity (recruit) carries with it a full set of data parameters, adding to model overhead and slightly increasing run time. This is not an 
elegant approach, but does allow future flexibility as more data is gathered or more applicant types are desired.

To implement the effects of station commander leadership and recruiter personality, we devised a preprocessor to modify parameters based on the connection between the leadership/personality survey and the duration survey conducted by Cordeiro and Friend (1998). We first regressed each measured model parameter (process duration or fail probability), against leadership and personality markers. This regression shows which leadership/personality markers affect each process duration or fail probability. We use an Excel spreadsheet to modify the appropriate process duration and fail probability parameters using the standardized regression coefficients. These modified parameters are then read into the simulation at the beginning of a set of runs.

\section{INITIAL OUTPUT ANALYSIS}

The first thing we considered when examining the simulation output was where the system entered steadystate. We began by running the simulation for thirty years and plotting the simulation time each contract was made against the contract's sequence number. We entered parameters for an average recruiter, and two slightly below average. The graph was nearly linear for the whole thirty years, with a small non-linearity in the beginning year. Next, we collected data from five replications of five years each. We plotted simulation time (the time a recruit was contracted) against sequence number once again. The results are shown in Figure 2.

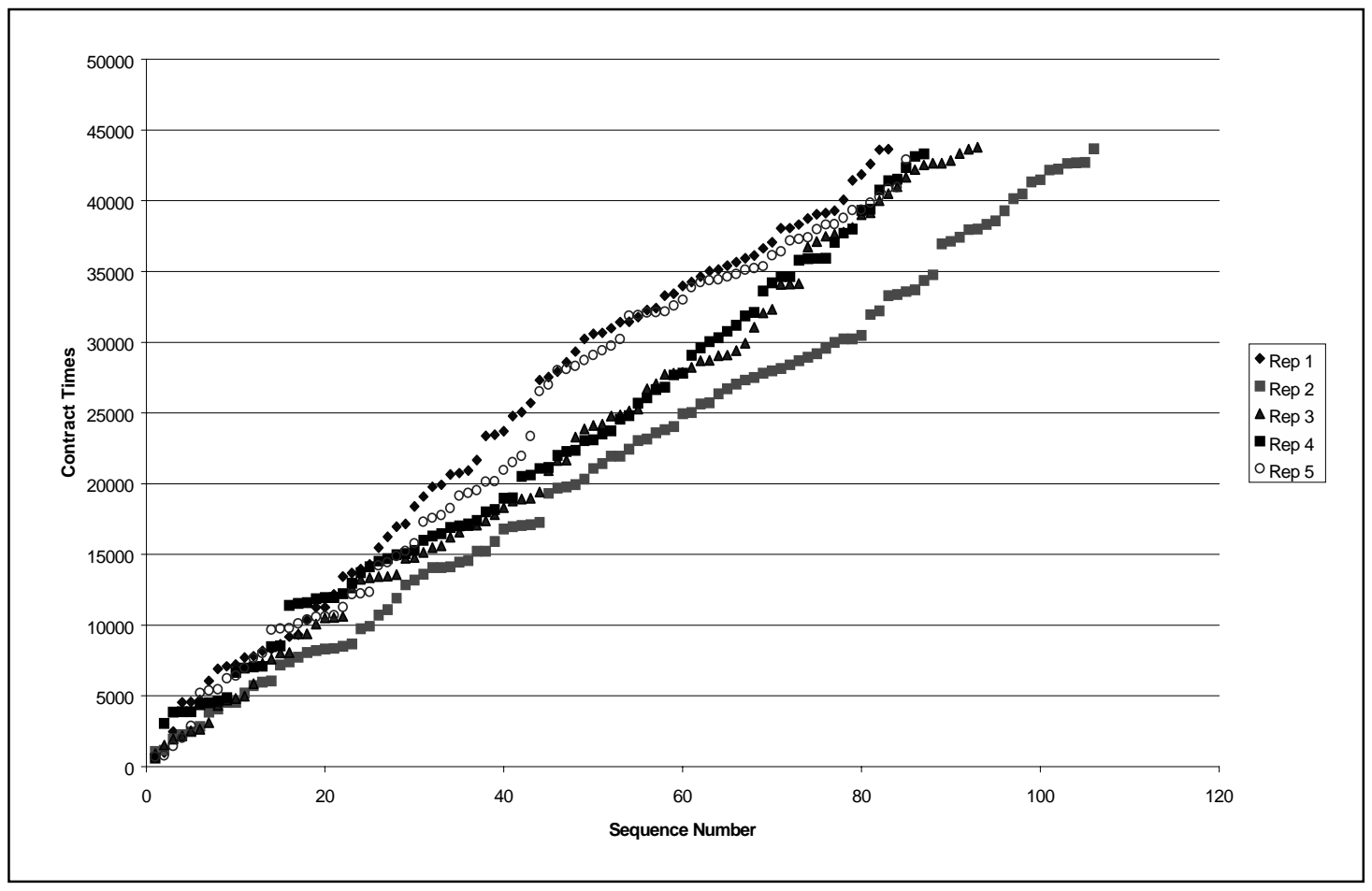

Figure 2: Time to Obtain Contract

Figure 2 shows simulation time (in hours) versus sequence number (the order in which the recruits were contracted.) It is easy to see that the graph for each replication is approximately linear, indicating that the times between contracts are approximately evenly spaced. We also note the number of contracts produced in this five year span ranged from approximately 80 (Rep 1) to just over 100 (Rep 2.) To gain a little more insight into the output, we plot time between contracts in Figure 3.

Figure 3 is read as follows. The individual dots represent individual observations of inter-contract times versus sequence number. For example, the first sequence number shown here is the difference in simulation time between the first two contracts. The relatively ragged line connecting the round dots represents the average intercontract time by sequence number across the five runs, which we call a sequence number average. The line labeled "moving average" represents the average of 21 (21 selected based on trial and error to obtain desired smoothing) sequence number averages. Using a moving average has the effect of smoothing the data, so we can tell where steady state conditions appear. If we examine the above graph, it appears inter-contract times are slightly high at first, and then settle into steady state by the $15^{\text {th }}$ 


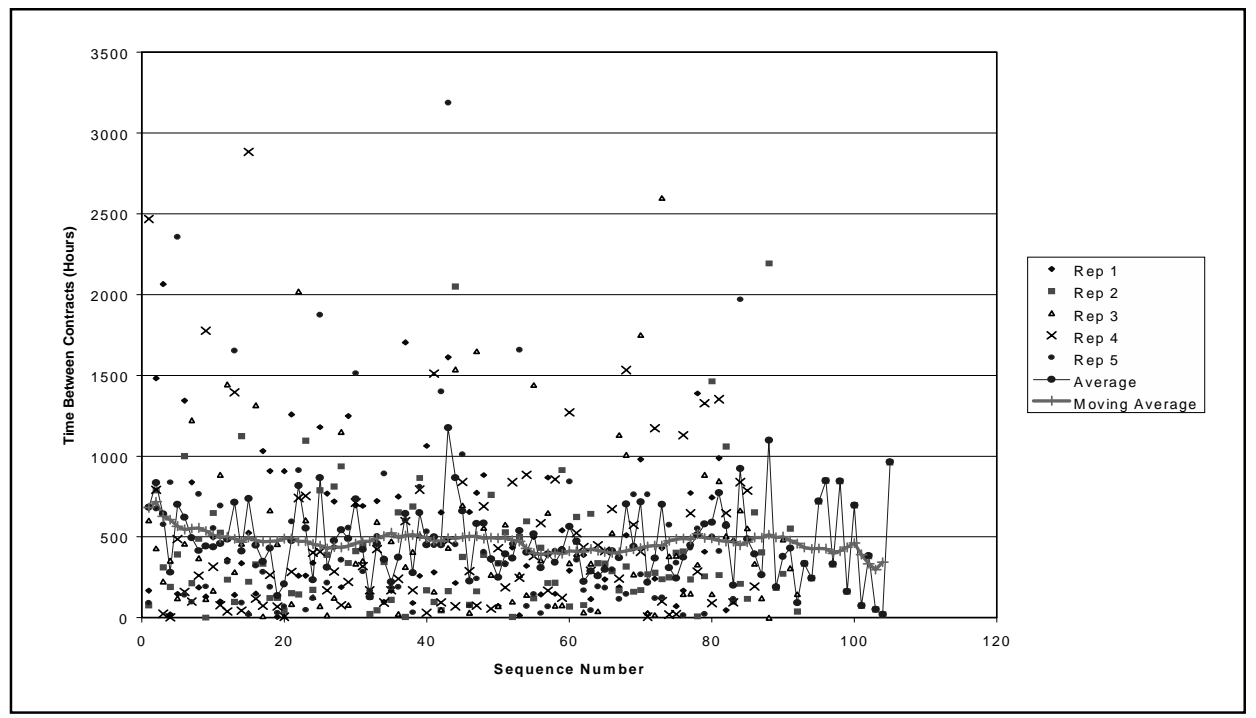

Figure 3: Average Inter-contract Time by Sequence Number

contract. When we cross-reference the $15^{\text {th }}$ contract with simulation times, we see that the $15^{\text {th }}$ contract occurs between the $10^{\text {th }}$ and $12^{\text {th }}$ month of the first year. Therefore, we can safely use a warm-up period of one year for our simulation. As a side note, the $n^{\text {th }}$ moving average of size 21 for the bulk of the points is calculated by summing the 21 values centered on the $n^{\text {th }}$ point and dividing by 21 . Therefore, each moving average point is simply the average of the nearest 21 points. At the start, we must use smaller sizes to average. For example, the first moving average is simply the first data point. The second moving average is the average of the first three data points, and so on, until we reach our chosen interval size of 21.

From the above graph, it is also interesting to note the maximum inter-contract times. Most fall below 1000 hours, but one is over 3000 hours, which translates to over four months for a team of three recruiters to get one contract. On the other hand, the steady-state time between contracts is very near 450 hours, or 18.75 days. This would mean the three-person team would average approximately 20 contracts per year. The average number of contracts per six months for our surveyed recruiters was 4.96 , so we would expect $4.96 * 3$ recruiters $* 2$ six month periods $=$ approximately 30 contracts per year. Therefore, we can see that our simulated recruiters are producing about $33 \%$ less than we would expect to see in the real world. This makes sense because of our choice of recruiter parameters in the model - one average, and two slightly less capable. In addition, although the numbers may never exactly predict our real-world average production, we are in the same range as the real world, and we can see how simulation output varies as we change our experimental settings.

\section{FUTURE RESEARCH}

Our initial look at leadership and personality effects was based on a small sample of data from the local Dayton area. We have recently received surveys back from hundreds of recruiters across each of the Army's five recruiting brigades. This data can be used in a multivariate analysis to further define leadership and personality effects and to improve our incorporation of these factors into the current, or a modified, recruiting station model.

Other areas of interest include looking at variations in the recruit flow in terms of contracts written, accessions, and recruit placements based on policy changes in timing and numbers of specific recruit types desired. For example, current practice typically involves going for the easier to sell, lower quality recruits up front, leaving the more difficult higher quality recruits to pull in at the end of the year. What is the effect of pushing hard to attract more high quality recruits early in the year? Another issue we are looking at is how best to aggregate a station level model up to the company level, and eventually to the brigade level.

\section{CONCLUSION}

This study consisted of much more data gathering research and less simulation than originally anticipated. However, without the proper data, the resulting simulation model would be worthless. We have developed a sophisticated survey tool and methodology to collect data to measure the recruiting station commander effect as well as recruiter personality effects. In addition, we formulated a procedure to incorporate these effects in our station level model. Finally, we made modifications to the model so it can incorporate eight different prospect types through the same 
basic recruitment flow. This research has already provided useful insight on effective station commander leadership qualities to the sponsor, United States Army Recruiting Command, in their continuing effort to recruit a quality force for the next millennium.

\section{REFERENCES}

Cordeiro, J. D., Jr., and M. A. Friend. 1998. Using Simulation to Model Time Utilization of Army Recruiters. Master's thesis, Air Force Institute of Technology.

Goldberg, L. R 1998. International Personality Item Pool. http:// ipip.ori.org.

Locke, E. A., and G. P. Latham. 1990. A Theory of Goal Setting and Task Performance. Englewood Cliffs, N.J.: Prentice-Hall.

McLarney, E. L. 1999. Simulating the Army Recruiting Station with Leadership Effects and Multi-quality Recruits. Master's thesis, Air Force Institute of Technology.

\section{AUTHOR BIOGRAPHIES}

EDWARD L. MCLARNEY is a Captain in the United States Army and an analyst at the National Simulation Center, Fort Leavenworth, Kansas. A 1989 graduate of the U.S. Military Academy at West Point, CPT McLarney received his M.S. in Operations Research from AFIT in 1999. His research interests include simulation programming and application.

J.O. MILLER is a Lieutenant Colonel in the United States Air Force and an Assistant Professor in the Department of Operational Sciences at the Air Force Institute of Technology (AFIT). He also serves as director of the Center for Modeling, Simulation and Analysis. A 1980 graduate of the U.S. Air Force Academy, Lt Col Miller received his M.S. in Operations Research from AFIT in 1987 and his Ph.D. in Industrial Engineering from The Ohio State University in 1997. His research interests include simulation, nonparametric statistics, and ranking and selection.

KENNETH W. BAUER, JR. is a retired United States Air Force Lieutenant Colonel and a Professor in the Department of Operational Sciences at the Air Force Institute of Technology. His research interests include the statistical aspects of neural networks and simulation modeling.

ROBERT FANCHER is a Major in the United States Army. He currently works as an Operations Research Analyst for the U.S. Army Recruiting Command. A 1987 graduate of the U.S. Military Academy at West Point, MAJ Fancher received his M.S. in Industrial Engineering from Texas A\&M University in 1997. 